\title{
Cerebellar Ependymal Tumor
}

National Cancer Institute

\section{Source}

National Cancer Institute. Cerebellar Ependymal Tumor. NCI Thesaurus. Code C131576.

An ependymal tumor affecting the cerebellum. 